\title{
JUSTIFICATION AND THE PSYCHOLOGY OF HUMAN REASONING*
}

\author{
STEPHEN P. STICH \\ University of Maryland \\ RICHARD E. NISBETT \\ University of Michigan
}

\begin{abstract}
This essay grows out of the conviction that recent work by psychologists studying human reasoning has important implications for a broad range of philosophical issues. To illustrate our thesis we focus on Nelson Goodman's elegant and influential attempt to "dissolve" the problem of induction. In the first section of the paper we sketch Goodman's account of what it is for a rule of inference to be justified. We then marshal empirical evidence indicating that, on Goodman's account of justification, patently invalid inferential rules turn out to be "justified." We conclude that something is seriously wrong with Goodman's story about justification. In the second section we attempt to patch Goodman's account. The notion of epistemic authority and the social aspect of justification play central roles in the alternative account of justification that we propose.
\end{abstract}

There was a time, Hume's time, when the empirical study of human reasoning went hand in hand with the philosophical study of the justification of inference. But more recently, philosophers have held the empirical study of reasoning to be beyond their province. And modern experimental psychologists, until recently, simply ignored human inference altogether. Happily, a growing number of experimental psychologists have begun to study how human subjects actually go about the business of reasoning. Philosophers, however, have as yet given this work little notice. We are convinced that philosophers ignore this work at their peril. ${ }^{1}$

The present paper makes an extended case for the philosophical relevance of recent empirical work on reasoning. The paper will focus on the implications of this work for an analysis of justification of inductive procedures. We shall argue that Nelson Goodman's elegant and enormously influential attempt to "dissolve" the problem of induction is seriously flawed. ${ }^{2}$ At the root of the difficulty is the

\footnotetext{
*Received June 1979; revised October 1979.

'For a parallel view, cf. Goldman (1978).

${ }^{2}$ References to this volume (Goodman 1965) will be given in parentheses in the text.
}

Philosophy of Science, 47 (1980) pp. 188-202.

Copyright (C) 1980 by the Philosophy of Science Association. 
fact that Goodman makes tacit assumptions about the ways in which people actually infer. These are empirical assumptions, and recent studies of inference indicate that the assumptions are false. This is the burden of the first section of our paper.

In the second section we try our hand at repairing the damage. The trouble with Goodman's story about induction centers on his analysis of what we are saying when we say that a rule of inference is justified. We will offer a new account of what is going on when people say that an inference or a rule of inference is (or is not) justified. In the course of developing our analysis we begin to explore the much neglected social component of justification and the role of expert authority in our cognitive lives.

\section{FACTS AND FICTIONS ABOUT FORECASTS}

\section{Goodman's Solution to the Riddle of Induction}

Hume's riddle about inductive reasoning is easy enough to state. We know that a certain kind of food has nourished us in the past, and on the basis of this evidence we come to believe it will continue to nourish us in the future. But what justification do we have for such an inference? Surely it is possible that food which nourished us in the past should poison us now. There is no contradiction in assuming that this will happen. More generally, what justification do we have for believing that the regularities we have observed in nature will obtain in those parts of nature we have yet to observe?

The central move in Goodman's solution to Hume's riddle is a strategic one. Before attempting a justification of inductive reasoning, Goodman notes, it would be sensible to reflect on just what it is we ask for when we ask for a justification. If, for example, what we seek is a guarantee that inductive inferences will turn out to be correct, then there can be no justification of induction. For there simply is no guarantee. Some good inductive arguments with true premises turn out to have false conclusions. That is just the nature of the beast. ${ }^{3}$ But if it is not a guarantee we seek, just what do

\footnotetext{
${ }^{3}$ Goodman makes the point with more grace though less caution:
}

If the problem is to explain how we know that certain predictions will turn out to be correct, the sufficient answer is that we don't know any such thing. If the problem is to find some way of distinguishing antecedently between true and false predictions, we are asking for prevision rather than for philosophical explanation. (62)

Read literally, Goodman seems to be claiming that we do not know some predictions will turn out to be correct while others will not. But surely this is perverse if the word 'know' is being used with its ordinary meaning. Suppose that a gypsy fortune 
we want when we ask for a justification of induction? Before we can productively ask for a justification of induction, we need an analysis of the notion of justification.

Goodman begins his analysis of justification by asking what a justification amounts to in the case of deductive reasoning. To begin, of course, a deductive inference is justified if it conforms to the general rules of deductive inference. But not just any set of rules will do here; the rules themselves must be valid ones. How, then, do we justify a deductive rule? On Goodman's view,

Principles of deductive inference are justified by their conformity with accepted deductive practice. Their validity depends on accordance with the particular deductive inferences we actually make and sanction. If a rule yields inacceptable inferences, we drop it as invalid. Justification of general rules thus derives from judgements rejecting or accepting particular inferences. (63-4)

Now, as Goodman notes, this account of justification "looks flagrantly circular." (64) Particular inferences are supposed to be justified by their conformity to general rules, and general rules are supposed to be justified by their conformity to valid inferences. But, Goodman urges, the

circle is a virtuous one. The point is that rules and particular inferences alike are justified by being brought into agreement with each other. $A$ rule is amended if it yields an inference we are unwilling to accept; an inference is rejected if it violates a rule we are unwilling to amend. The process of justification is the delicate one of making mutual adjustments between rules and accepted inferences; and in the agreement achieved lies the only justification needed for either. (64, emphasis Goodman's)

So, on Goodman's account, a deductive rule is justified if it accords with the deductive inferences that we would reflectively make or sanction. We shall refer to this sort of accord by saying that a rule is in reflective equilibrium with inferential practice. ${ }^{4}$

Finally, Goodman proposes that his account of justification in deduction can be extended mutatis mutandis to inductive reasoning as well. There too, a particular inference is justified by conformity

teller predicted last week that the sun would not rise yesterday. We certainly think that we knew her prediction would turn out not to be correct even before yesterday's sunrise. And as the word ' $\mathrm{know}$ ' is ordinarily used, we are surely right.

${ }^{4}$ We borrow the term reflective equilibrium from John Rawls (1971, p. 20). Rawls, in turn, attributes the idea to Goodman. 
to general rules, in this case the rules of induction. And the general principles are justified by their conformity to the inductive references we reflectively make and accept.

Predictions are justified if they conform to valid canons of induction; and the canons are valid if they accurately codify accepted inductive practice. (64)

There is an elegant simplicity to Goodman's account. To justify a particular inductive inference we need only show that it conforms with justified rules of inductive inference. And to justify the rules we need only show that they accurately describe the inductive inferences we are willing to accept. Actually, the portrayed simplicity of the justificatory process is a bit deceptive. For there may be those awkward times when a rule we are loathe to amend sanctions an inference we are unwilling to accept. And conversely there may be times when canons of induction which we are reluctant to fiddle with fail to sanction an induction we are unwilling to reject. Here Goodman's counsel is that we resort to the "delicate" process of making mutual adjustments between rules and accepted inferences, though he gives us no guidance on how to resolve the competing claims of an irresistible inference and an immovable rule. His view would seem to be that there is no right or wrong way to resolve such an impasse, or at least that any of a wide range of potential resolutions are all equally acceptable. ${ }^{5}$ For our purposes, however, we may ignore those problematic cases where rule and inference conflict. In the remaining cases, those where a rule we are inclined to endorse sanctions inferences we are inclined to accept, Goodman takes both rule and inferences to be justified.

A conspicuous virtue of Goodman's account of justification is that, if it is correct, then the problem of induction is straightforwardly solvable. Hume asked what justification we have for believing that bread will continue to nourish us. The answer is that we have inferred this belief from true premises via valid inductive rules. And if Hume were to ask what justification we have for the rules, the reply would be that they are in reflective equilibrium with our inductive practice. There remains, of course, the formidable job of explicitly articulating the rules which capture our reflective practice. This is the project which occupies the remainder of Goodman's book. However, we will retrace Goodman's thinking no further, for it is our contention that his account of justification is simply wrong. 


\section{Some Troublesome Facts About Human Inference}

What we propose to show is that, pace Goodman, being in reflective equilibrium with inductive practice is neither necessary nor sufficient for a rule of inductive inference to be justified. Our strategy will be to take the reflective equilibrium idea seriously and ask what sorts of rules do, as a matter of empirical fact, pass the reflective equilibrium test. Pursuing this course we will find numerous examples of patently invalid rules which pass the test for many subjects. In most of these cases there will be a valid rule which fails to pass the reflective equilibrium test. Some of the cases we will cite rest heavily on anecdotal evidence, and on conjecture about what more careful study would show. However, there is also a growing body of empirical work which points to the conclusion that human subjects regularly and systematically make invalid inductive inferences. While some of these studies provide little evidence about subjects' explicit acceptance of the invalid rule tacitly guiding their inferences, there is no reason to think that they would have any qualms about accepting these invalid rules, or about rejecting valid ones that ought to govern the inference at hand.

\section{i. The Gambler's Fallacy}

To begin, let us consider the notorious case of the gambler's fallacy. Most readers will be able to provide their own anecdote of a person involved in a game of chance like roulette who has been losing heavily while betting on a certain number. In some circumstances it might be reasonable for the subject to infer that the game itself is crooked. In other circumstances, where the hypothesis of a dishonest game can be ruled out as extremely unlikely, the reasonable expectation is that the chance of hitting the favored number after a long losing streak is exactly the same as the chance of hitting the number at any other time. But the subject of our anecdote makes neither inference. Rather, his losing streak leads him to stick all the more doggedly to his favored number, in the belief that the chance of hitting that number increases as the number of turns in which it fails to win increases. The anecdote has two possible endings. In one, the subject does hit the jackpot, thus reinforcing his adherence to the gambler's fallacy. In the other, the subject leaves the game in a barrel, either metaphorically or literally.

The principle of inference invoked by our misguided subject would seem to be something like the following:

In a fair game of chance, the probability of a given sort of outcome occuring after $n+1$ consecutive instances of non-occurrence is greater than the probability of its occurrence after $n$ consecutive instances of non-occurrence. 
There can be little doubt that many people do in fact persistently infer in accord with this principle. So the principle does accurately describe the inductive practice of these subjects. Moreover, there is no reason to think that if these subjects were explicitly queried about whether the rule is intuitively reasonable or acceptable to them they would be at all reluctant to endorse it. Indeed a number of reflective people have endorsed the gamber's fallacy principle. Consider, for example, the following eye-catching passage from Henry Coppée's Elements of Logic (Revised edition, 1874; Philadelphia: J. H. Butler \& Company, p. 162).

Thus, in throwing dice, we cannot be sure that any single face or combination of faces will appear; but if, in very many throws, some particular face has not appeared, the chances of its coming up are stronger and stronger, until they approach very near to certainty. It must come; and as each throw is made and it fails to appear, the certainty of its coming draws nearer and nearer. ${ }^{6,7}$

Now the existence of large numbers of subjects like Coppée is something of an embarrassment to Goodman. The gambler's fallacy rule is in reflective equilibrium with actual inductive practice for these subjects. So on Goodman's account of justification, both the gambler's fallacy and the inferences made in accord with it are justified for these subjects.

\section{ii. Regression Errors}

To introduce our second example, consider the following little quiz: It is well known that people's height is correlated with the height of their parents. Tall persons generally have tall parents and short persons generally have short parents, though of course there are exceptions. Now consider those families in which both parents are in the 95th percentile for height. That is, the father is taller than $94 \%$ of all men and the mother is taller than $94 \%$

\footnotetext{
${ }^{6}$ We are grateful to Prof. Arnold Wilson for bringing this quote to our attention. There is a delightful irony in the fact that Coppée's book first appeared while he was Professor of Philosophy at the University of Pennsylvania. Goodman held the same position when Fact, Fiction and Forecast first appeared.

${ }^{7}$ Perhaps we should note that there are circumstances in which an inferential strategy similar to the gambler's fallacy would be perfectly appropriate. Suppose you are waiting for an elevator, but you could walk up the stairs. The longer you wait, the more likely the elevator is to come in the next few seconds (assuming that the elevator is functioning properly and is going through its appointed rounds). It is tempting to conjecture that the gambler's fallacy has its psychological roots in an overgeneralization. An inferential strategy which is perfectly reasonable in a given range of cases is extended to other cases where it is inappropriate. (For the example our thanks go to an anonymous reviewer.)
} 
of all women. What would you expect the average height of children in these families to be?

(a) Taller than the 95th percentile height

(b) Shorter than the 95th percentile height

(c) Approximately equal to the 95th percentile height.

Most subjects who take this little quiz answer c, though, of course, the correct answer is b since regression toward the mean is to be expected in such cases. Extensive work by Kahneman and Tversky (1973) has demonstrated that most subjects have little or no grasp of the notion of statistical regression. In a wide range of cases in which a pair of dimensions are imperfectly correlated (e.g. student I.Q. and grade point average; or success in graduate school and success in career), subjects expect that values on the dimension to be predicted will on the average be as discrepant from the mean as values on the predictor dimension. Moreover, when questioned on the principle behind their inference, the rules offered by subjects take no account of regression to the mean. ${ }^{8}$ These subjects, like those in the gambler's fallacy example, pose a problem for Goodman. Their non-regressive rule is in reflective equilibrium with their actual inductive practice. So for Goodman, both their rule and their individual inferences are justified.

\section{iii. Erroneous Analysis of Covariation}

As a final example, consider the sort of inference that sometimes leads people to believe in the efficacy of quack medical "cures," occasionally with tragic results:

Aunt Maude has been all but crippled with painful backaches. On the advice of a friend, she seeks treatment from Dr. Snapbone. After three months in Snapbone's care, Maude's backaches are entirely gone. On hearing of Aunt Maude's “cure," Uncle Rupert comes to believe that Dr. Snapbone's treatment is helpful for backaches, i.e. that one's chances of recovery are better with Snapbone's treatment than without.

Of course, without information about the spontaneous "cure" rate among persons whose backaches are left untreated, along with information about the rate of both "cures" and "non-cures" among people who have received Snapbone's therapy, Rupert is in no position to draw the inference he does. However, Smedslund and Ward and

\footnotetext{
${ }^{8}$ For a more detailed account of the rule which subjects endorse, cf Nisbett \& Ross (1980).
} 
Jenkins ${ }^{9}$ have shown that many subjects take no account of information about spontaneous "cures" even when the information is available. Given data like the following:

$\begin{array}{lcc} & \text { Cure } & \text { No Cure } \\ \text { treatment } & 581 & 83 \\ \text { no treatment } & 287 & 41\end{array}$

many subjects will conclude that the chances of a cure are better with treatment than without. Such subjects often point to the treatment/cure cell of the matrix and say, "many people who got the treatment were cured, so the treatment is effective." Other subjects, slightly more sophisticated, point to the treatment/no cure cell in addition, and say, "since most of the subjects who received the treatment were cured, the treatment was effective." In fact, these data provide no evidence that the treatment has any value whatever. Yet subjects in these experiments are prepared to endorse the fallacious rule they appear to be using, viz.

If the presence of $A$ (in this case treatment) is often followed by the presence of $B$ (in this case cure) then the chance of $B$ occurring is greater when $A$ has occurred than when $A$ has not occurred.

As in our previous two examples, such subjects are an embarrassment for Goodman. The rule they endorse is in reflective equilibrium with their actual inductive practice. So on Goodman's account of justification both the rule and the particular inference are justified.

The examples we have elaborated are not the only ones that might be given. In the last two decades psychologists have become increasingly interested in the inferential patterns people actually invoke and accept in ordinary life. ${ }^{10}$ The picture that emerges from this work is hardly a flattering one. Subjects frequently and systematically invoke inference patterns ranging from the merely invalid to the bizarre. And, though the evidence is less substantial on this point, there is every reason to think that many of these patterns are in reflective equilibrium.

\section{Some Countermoves}

On the face of it, the facts we have reviewed would seem to show that Goodman's account of justification is well off target. In the next few pages we want to anticipate and respond to possible moves

\footnotetext{
${ }^{9}$ Smedslund (1963); Ward and Jenkins (1965).

${ }^{10}$ See especially Tversky and Kahneman (1974) and Nisbett \& Ross, (1980).
} 
a Goodmanian might make in an effort to shield his view from the damage threatened by the facts.

\section{i. Instruction and Reflective Equilibrium.}

The first move we want to examine denies that the rules invoked by subjects in our examples actually are in stable reflective equilibrium. The Goodmanian who makes this move grants that subjects do frequently infer in accordance with these invalid rules, and do accept the rules when questioned. However, he continues, reasonable subjects can be shown the error of their ways. We can, with a bit of effort, teach these subjects that the inferential principle they accept is an invalid one. To do this we might show the subjects that the rule they use is in conflict with other rules they also accept, or with beliefs they already have or can be gotten to acquire. With appropriate instruction they can be weaned away from their invalid rules. Now, the Goodmanian claims, for a rule to be in stable reflective equilibrium is not merely for it to codify actual inductive practice. An inferential principle is in stable reflective equilibrium only when it codifies inferential practice and also would survive the further reflective process of carefully comparing rules with each other and with the beliefs subjects have or can be led to have. Since the principles considered in the previous section do not pass this test they are not counter-examples to Goodman's account of justification.

Before attempting to parry this move, let us note one claim made by our hypothetical Goodmanian with which we have no quarrel. It is quite true that a rational subject often can be persuaded to reject an invalid rule in favor of a valid one. It has been our experience, for example, that a subject who endorses the gambler's fallacy can often be led to reject the rule by asking him to consider whether he thinks there is any causal relation between past throws of dice and future throws of the same dice. When the subject concedes that there is no such causal relation, we ask him to consider how it could be that long runs in which a certain number does not appear are followed by higher probabilities of that number appearing, unless there is a causal relation between past and future throws. Stymied by the question, the subject is quite receptive to the suggestion that with fair dice the chance of a given number appearing is independent of the outcome of preceding tosses.

However, we do not think that the teachability of rational subjects can save Goodman from our counterexamples. The problem is that teachability is a two-edged sword. While it is quite true that subjects can often be gotten to reject invalid rules they had previously accepted, it is also true that they can be gotten to accept invalid rules they had previously rejected. For example, we have gotten a few subjects 
to wonder about their rejection of the gambler's fallacy by arguing as follows: "If the coin is a fair one, then in the long run the number of heads and tails should be about equal. But then if a fair coin produces a long run of heads, there will have to be some excess of tails in the following flips in order to achieve the rough equality expected from a fair coin." For obvious moral reasons we did not pursue this line of argument to the point where the subjects became converts to the gambler's fallacy. But there is little reason to doubt that such an effort at persuasion would often meet with success, particularly when the subject is, say, an undergraduate largely innocent of formal training in statistics, and the people offering the arguments are authority figures, perhaps university professors. Our point, then, is that with suitable argument subjects can often be convinced of an invalid rule just as they can be convinced of a valid one. What is more, we know of no reason to think that valid rules are easier to teach than plausible invalid ones. Indeed, because of the counter-intuitive nature of some inductive rules, regression principles, for example, there is good reason to suppose that some invalid rules would be substantially easier to teach, and more stable once learned.

Now recall that our imagined Goodmanian proposed to save Goodman's account of justification by interpreting the standards for reflective equilibrium more stringently. To be in stable reflective equilibrium a rule must not only accord with inferential practice, it must also survive careful comparison with other rules the subject accepts and with the body of beliefs he either has or may acquire during the reflective process. Our rejoinder is simply this. There is no reason to think that this more stringent reflective process would have a unique outcome for a given subject. With suitable "guidance" many subjects could be led either to accept or reject a large number of inferential principles, both valid and invalid.

\section{ii. Digging In}

There is a second strategy a Goodmanian might try in an effort to protect his account of justification from our embarrassing facts. This is the bold strategy of simply digging in his heels and insisting that whatever inferential principles pass the reflective equilibrium test are indeed justified, at least for the subjects involved. The subject, it might be argued, has no higher court of appeal than the reflective equilibrium test. So if the principles cited are in reflective equilibrium for the subjects in question, then the rules are justified for them. Of course, the rules are not justified for us. But no matter. They are justified for the subjects who invoke them, and that is all Goodman's theory need claim.

We are a bit hard put to reply to our imagined Goodmanian. For 
he is denying a premise we took to be completely obvious. In our critique of Goodman we simply assumed that the craps shooter in Las Vegas who systematically invoked and acted on the gambler's fallacy was relying on a patently invalid rule. Perhaps the best reply is to remind ourselves of just what we are up to. Goodman proposed to (dis)solve the problem of induction by first analyzing what we mean when we say an inferential principle is justified. And the test of such an account, surely, is how well the proposed analysans captures the extension of our intuitive use of the analysandum. By our lights it is no less than bizarre to suggest that the gambler's fallacy is justified for the Las Vegas crap shooter. This judgement seems to be all but universally shared by native philosophical informants.

\section{II}

\section{AN ANALYSIS OF JUSTIFICATION}

It is time for us to stick our own necks out a bit and offer our account of justification. The story we have to tell is a complicated one, best set out in pieces. To begin we will sketch an account of justification that is, we think, almost right. We will then go on to say why our account is only a near miss, and how it fits into the more complicated story of how the notion of justification is used.

\section{Epistemic Authority: The Social Component of Justification}

Why does Goodman's account of justification fail? A suggestive way to approach this question is to reflect on the sort of defense one of our imagined Goodmanians offered for the Las Vegas crap shooter: "The subject has no higher court of appeal than the reflective equilibrium test." The suggestion left tacit is that the alternative to the reflective equilibrium test is skepticism. Once he has established that a rule is in reflective equilibrium with his own inductive practice, the subject has done everything he can do. If this is not enough to show the rule in question is justified, then the subject might invoke an unjustified rule though he could never know he was doing so. But surely all of this is quite wrong. There is a higher court of appeal than this subject's reflective equilibrium. It is the reflective equilibrium of his cognitive betters. There are people in our subject's society who are recognized as authorities on one or another sort of inference. And if our subject wanted to appeal to a higher court than his own reflective equilibrium, he could do so. He need only seek out the experts and ask them.

The role of experts and authorities in our cognitive lives has been all but ignored by modern epistemologists. Yet it is a hallmark of 
an educated and reflective person that he recognizes, consults and defers to authority on a wide range of topics. We defer to the judgment of experts not only in assessing inference, but on factual questions as well, in medicine, science, history, and many other areas. Few educated laypersons would consider questioning the consensus of authorities on the authenticity of a painting, the cause of an airline crash, or the validity of a new theorem. Indeed, it is our suspicion that one of the principle effects of education is to socialize people to defer to cognitive authorities. (We are following up our hunch in an empirical study now underway.)

Deference to authority is not merely the habitual practice of educated people, it is, generally, the right thing to do, from a normative point of view. The man who persists in believing that his theorem is valid, despite the dissent of leading mathematicians, is a fool. The man who acts on his belief that a treatment, disparaged by medical experts, will cure his child's leukemia, is worse than a fool.

Of course, it is rarely the case that even a well educated person actually knows who the experts on a given topic are. And it is even more infrequent that he seeks them out or reads what they have written. It is more common to rely on second hand accounts in the popular press, though the extent and influence of such second hand appeals to authority is very much an open question. In claiming that people recognize the force of cognitive authority, we are not claiming that they often consult such authorities, but only that people believe there are experts and that they are prepared to defer to the experts' views. ${ }^{11}$

The last three paragraphs constitute little more than a gesture at the phenomena of epistemic authority. There are many questions about the social psychology and sociology of epistemic authority that must be explored before we have even the beginnings of an adequate understanding of the subject. Perhaps the most interesting question concerns the vesting of epistemic authority: In virtue of what do people come to count as experts on a given issue for a society or a subculture? Yet another set of questions focuses on opinion change among the community of experts: Are there general patterns to be observed? What factors influence the dynamics of opinion change among experts? In addition, it would be fascinating to know the extent to which subcultures within our society recognize disparate sets of experts on one or another issue. Equally intriguing is the question of what happens when cultures recognizing different experts come in contact with one another. Plainly, this is not the place to essay

\footnotetext{
${ }^{11}$ For some related remarks, see Hilary Putnam (1975, pp. 127-9).
} 
answers to these questions. Our purpose here is only to urge the importance of the questions and to lament their neglect.

The relevance of the notion of epistemic authority to Goodman's ailing analysis of justification will become clear by returning to a consideration of our Las Vegas crap shooter. Why is it that his inference is not justified? The answer we would urge is that the rule he invokes, though in reflective equilibrium for him, is not in reflective equilibrium for the experts on inductive inference in our society. This suggests a modification of Goodman's account which recognizes the special role of cognitive authorities. On the modified account, a rule of inference is justified if it captures the reflective practice not of the person using it but of the appropriate experts in our society. We think that this "expert reflective equilibrium" (hereafter: expert r.e.) account of justification does a much better job than Goodman's account at capturing what one does when attributing and denying justification. In particular, it handles with dispatch all the examples assembled in I,2. Each of these was an example of an invalid inferential rule accepted and adhered to by many subjects. On the expert r.e. account, in contrast to Goodman's, none of these rules is justified, since none are accepted by experts on inference.

It has been suggested to us that, read with maximal charity, Goodman might actually be construed as offering the expert r.e. account himself. Goodman's account of justification refers to "inferences we actually make and sanction," inferences "we are willing to accept," rules "we are unwilling to amend," etc. Unfortunately he never pauses to say who "we" are. Now on the most charitable reading, Goodman's "we" is taken to refer only to himself and other authorities on inductive inference. This reading of Goodman strikes us as an unlikely one, in light of his total silence on the matter of cognitive authority. But if this is the intended interpretation, our disagreements with Goodman are still not at an end. We do not think the expert reflective equilibrium account of justification is the right one.

\section{The Cognitive Rebel And The Analysis Of Justification}

The difficulty we see with the expert r.e. account is that it ties the notion of justified inference too closely to the reflective equilibrium of socially designated authorities. To knowingly disagree with expert opinion is frequently seen as foolish. But on the expert r.e. view, it is more than foolish, it is self-contradictory. Consider the case of the subject who espouses an inferential principle while knowing full well that the experts of our society consider the principle to be unjustified. Such a subject might say, "I have thought about the principle carefully and I think it is a justified one; I realize that 
the recognized authorities reject the principle, but $I$ think they are wrong." Now on the expert r.e. account, our subject is literally contradicting himself. $\mathrm{He}$ is saying that the principle both does capture the reflective practice of the authorities (is justified, on the expert r.e. account), and that it does not. We take this consequence of the expert r.e. analysis to be unacceptable. The person who refuses to defer to socially recognized cognitive authority is often regarded as unwise, but not quite that unwise. He is not literally contradicting himself. ${ }^{12}$ What we need, then, is some account of justification which gives the cognitive rebel his due. The cognitive rebel is, in effect, proclaiming that the reflective equilibrium of socially designated authorities doesn't count, and that his own reflective equilibrium is, for the matter at hand, to be preferred. Since he can carry off his proclamation without contradiction, our analysis cannot make the reflective equilibrium of socially designated experts necessary or sufficient for justification.

On our amended view, an attribution of justification to a rule of inference can be unpacked as a claim that the rule accords with the reflective inductive practice of the people the speaker takes to be appropriate. But the attribution of justification does not, by itself, specify whose reflective equilibrium the speaker takes to be appropriate. That job of specification can be done in varying ways by the context of the utterance. Or it can be left quite open or ambiguous. So, on the view we are urging,

Rule $r$ is justified

is to be analyzed as:

Rule $r$ accords with the reflective inferential practice of the (person or) group of people I (the speaker) think appropriate.

Now most people are cognitive conservatives most of the time. They take the appropriate group to be the socially, consensually, designated authorities. The disagreement between the cognitive rebel and the cognitive conservative is, in effect, a dispute over whose reflective judgment ought to be heeded in the issue at hand. On our view, such disputes are not exclusively cognitive disputes. They are better viewed on the model of political disputes whose resolution, like the resolution of other political disputes, is determined by such factors as social power, personal style and historical accident. There is something a bit radical about the view we are urging. To take some of the sting out, we should note that our view leaves abundant

\footnotetext{
${ }^{12}$ We are indebted to Allan Gibbard who first urged this argument on us.
} 
room for rational argument about justification among cognitive conservatives. Also, there may be rational argument about justification among cognitive rebels who agree about the appropriate authority group. However, if our account succeeds in capturing what we mean when we say that an inference is justified, then it is to be expected that there will be some disputes over justification that admit of no rational resolution. It is our guess that the history of scientific revolutions will provide examples of such disputes. And we expect that another, richer, source of examples would come from a careful study of the social psychology of cranks and scientific "crackpots," those forelorn souls who proclaim cognitive revolutions that win no converts. But to elaborate on this theme would require another paper, and another pair of authors.

\section{REFERENCES}

Goldman, A. (1978), Epistemics: The Regulative Theory of Cognition. Journal of Philosophy 75: 10, 509-523.

Goodman, N. (1965), Fact, Fiction and Forecast. Indianapolis: Bobbs-Merrill (second edition).

Goodman, N. (1966), The Structure of Appearance. Indianapolis: Bobbs-Merrill (second edition, chapter I.).

Nisbett, R. and Ross, L. D. (1980), Human Inference: Strategies and Shortcomings. Englewood Cliffs, N.J.: Prentice-Hall.

Putnam, H. (1975), “The Meaning of 'Meaning',' in H. Putnam's Mind, Language and Reality. Cambridge: Cambridge University Press, pp. 127-9.

Rawls, J. (1971), A Theory of Justice. Cambridge, Mass: Harvard University Press, p. 20.

Smedslund, J. (1963), "The concept of correlation in adults." Scandinavian Journal of Psychology 4, pp. 165-173.

Tversky, A. and Kahneman, D. (1974), "Judgment under certainty: Heuristics and Biases." Science 185, pp. 1124-1131.

Ward, W. D. and Jenkins, H. M. (1965), "The display of information and the judgment of contingency." Canadian Journal of Psychology 19, pp. 231-241. 